\title{
Hematopoietic Stem Cell Transplant for Hematological Malignancies: Experience from a Tertiary Care Center in Northern India and Review of Indian Data
}

\author{
Sanjeev Kumar Sharma ${ }^{1}$ Dharma Choudhary ${ }^{1}$ Divya Doval $^{1}$ Vipin Khandelwal ${ }^{1}$ Rasika Setia ${ }^{1}{ }^{1}$ \\ Tina Dadu ${ }^{1}$ Anil Handoo ${ }^{1}$ \\ ${ }^{1}$ Center for Bone Marrow Transplant, BLK Super Speciality Hospital, \\ New Delhi, India \\ Address for correspondence Sanjeev Kumar Sharma, MD, DM, Center \\ for Bone Marrow Transplant, BLK Super Speciality Hospital, New Delhi, \\ 110005, India (e-mail: sksanjeev13@yahoo.com).
}

South Asian J Cancer 2022;11(1):62-67.
Abstract

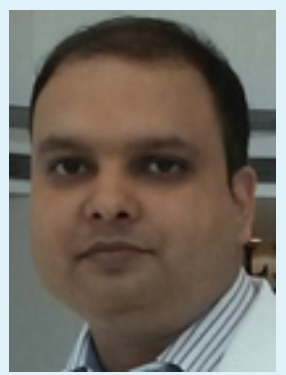
Sanjeev Kumar Sharma
Keywords
- leukemia
- lymphoma
- myeloma
- matched sibling donor
- allogeneic
- haploidentical of the disease.
- stem cell transplant
- overall survival
- infections
- GVHD

Hematopoietic stem cell transplantation (HSCT) is the preferred treatment for high-risk and relapsed/refractory hematological malignancies. Moreover, with the improved supportive care and increasing acceptance of haploidentical transplantations as an alternative treatment modality, more patients are opting for HSCT as a definite treatment for hematological malignancies. We report here the real-world data and outcome of HSCT done for hematological malignancies at our transplant center. Five hundred and sixteen patients underwent HSCT from August 2010 to November 2019. The most common indications for allogeneic and autologous HSCT were acute myeloid leukemia and multiple myeloma, respectively. The 5-year overall survival and diseasefree survival for all transplants were $65 \%$ and $33 \%$, respectively. Though outcome of matched sibling donor allogeneic transplant is better than haploidentical donor (HID) transplant, patients having only HID can still be considered for allogeneic HSCT for high-risk diseases. The most common cause of death was infections followed by relapse

\section{Introduction}

Hematopoietic stem cell transplantation (HSCT) is the preferred treatment for high-risk and relapsed/refractory (RR) hematological malignancies. Acute myeloid leukemia (AML) and multiple myeloma (MM) are the most common hematological malignancies requiring HSCT. There is scarcity of data on the feasibility and the outcome of autologous and
DOI https://doi.org/10.1055/s-0041-1731599 ISSN 2278-330X

How to cite this article: Sharma SK, Choudhary D, Doval D et al. Hematopoietic Stem Cell Transplant for Hematological Malignancies: Experience from a Tertiary Care Center in Northern India and Review of Indian Data South Asian J Cancer 2022;11(1):62-67. (c) 2021. MedIntel Services Pvt Ltd. All rights reserved.

This is an open access article published by Thieme under the terms of the Creative Commons Attribution-NonDerivative-NonCommercial-License, permitting copying and reproduction so long as the original work is given appropriate credit. Contents may not be used for commercial purposes, or adapted, remixed transformed or built upon. (https://creativecommons.org/licenses/by-nc-nd/ 4.0/)

Thieme Medical and Scientific Publishers Pvt. Ltd., A-12, 2nd Floor, Sector 2, Noida-201301 UP, India 
allogeneic stem cell transplant from the developing countries. We report here the real-world data on the outcome of HSCT done at our transplant center.

\section{Materials and Methods}

Five hundred and sixteen patients who underwent HSCT at BLK Super Speciality Hospital, New Delhi, India, from August 2010 to November 2019, were evaluated retrospectively using hospital information system and medical records. Informed consent was taken from all patients, and the study was approved by hospital ethical committee and institutional review board. The transplants were conducted in highefficiency particulate air-filtered rooms. All patients received conditioning regimens as per transplant protocols and transplant physician's discretion depending upon the type of disease and patient's performance status.

Conditioning intensity was defined as per the Consensus Center for International Blood and Marrow Transplant Research criteria. ${ }^{1}$ Myeloablative conditioning (MAC) regimens were defined by busulfan ( $\mathrm{Bu}$ ) dose $>6.4 \mathrm{mg} / \mathrm{kg}$ intravenously, whereas reduced intensity conditioning (RIC) regimens were defined by Bu dose $\leq 6.4 \mathrm{mg} / \mathrm{kg}$ intravenously and melphalan $(\mathrm{Mel}) \leq 150 \mathrm{mg} / \mathrm{m}^{2}$ intravenously. The various RIC conditioning regimens used were fludarabine (Flu)/Mel (Flu $30 \mathrm{mg} / \mathrm{m}^{2}$ intravenously for 5 days and Mel $140 \mathrm{mg} / \mathrm{m}^{2}$ intravenously for 1 day), $\mathrm{Flu} / \mathrm{Bu}$ (Flu $30 \mathrm{mg} / \mathrm{m}^{2}$ intravenously for 5 days and $\mathrm{Bu} 3.2 \mathrm{mg} / \mathrm{kg} /$ day intravenously for 2 days), Flu/Ara-C/idarubicin/Mel (Flu $30 \mathrm{mg} / \mathrm{m}^{2}$ intravenously for 5 days, cytarabine $2 \mathrm{~g} / \mathrm{m}^{2}$ intravenously for 5 days, idarubicin $8 \mathrm{mg} / \mathrm{m}^{2}$ intravenously for 3 days, and $\mathrm{Mel} 140 \mathrm{mg} / \mathrm{m}^{2}$ intravenously for 1 day), and Flu/cyclophosphamide (Cy) (Flu $30 \mathrm{mg} / \mathrm{m}^{2}$ intravenously for 5 days and Cy $60 \mathrm{mg} / \mathrm{kg}$ intravenously for 2 days). MAC regimen included $\mathrm{Bu} / \mathrm{Cy}$ ( $\mathrm{Bu} 3.2$ $\mathrm{mg} / \mathrm{kg} /$ day intravenously for 4 days and $\mathrm{Cy} 60 \mathrm{mg} / \mathrm{kg}$ intravenously for 2 days), Cy/total body irradiation (TBI) (Cy $50 \mathrm{mg} / \mathrm{kg}$ intravenously for 3 days and TBI 200 cGy twice daily for 3 days), and Flu/Bu 4 (Flu $40 \mathrm{mg} / \mathrm{m}^{2}$ intravenously for 4 days and Bu $3.2 \mathrm{mg} / \mathrm{m}^{2}$ intravenously once daily for 4 days).

The non-myeloablative haploidentical donor (HID) transplant protocol consisted of Flu/Cy/TBI (Cy $14.5 \mathrm{mg} / \mathrm{kg} /$ day intravenously for 2 days, Flu $30 \mathrm{mg} / \mathrm{m}^{2} /$ day intravenously on days 5 days, and TBI 200 cGy on day -1 ), whereas the myeloablative HID transplant protocol consisted of $\mathrm{Flu} / \mathrm{Bu} /$ Cy (Flu $25 \mathrm{mg} / \mathrm{m}^{2}$ intravenously for 5 days, Bu $110 \mathrm{mg} / \mathrm{m}^{2}$ intravenously for 4 days, and Cy $14.5 \mathrm{mg} / \mathrm{kg}$ for 2 days). Donor-specific antibodies were done using single bead assay for all patients undergoing HID transplants.

For autologous HSCT, MM patients received Mel 200 $\mathrm{mg} / \mathrm{m}^{2}$ (11 patients received Mel $140 \mathrm{mg} / \mathrm{m}^{2}$ ) and lymphoma patients received BEAM (BCNU $300 \mathrm{mg} / \mathrm{m}^{2}$ on day -6 ; etoposide $200 \mathrm{mg} / \mathrm{m}^{2}$ on days -5 to -2 [total dose $800 \mathrm{mg} / \mathrm{m}^{2}$ ], cytarabine $200 \mathrm{mg} / \mathrm{m}^{2}$ twice daily on days -5 to -2 [total dose $1600 \mathrm{mg} / \mathrm{m}^{2}$ ], and Mel $140 \mathrm{mg} / \mathrm{m}^{2}$ on day -1 ) as conditioning regimens before transplant. Stem cells were infused on day 0 . For myeloma patients peripheral blood hematopoietic stem cells (PBSCs) were noncryopreserved and for lymphoma patients PBSCs were cryopreserved.
PBSC harvest was done in blood bank and bone marrow harvest was done in the operation theater under general anesthesia. Posttransplant graft versus host disease (GVHD) prophylaxis included methotrexate, cyclosporine, or posttransplant cyclophosphamide $(50 \mathrm{mg} / \mathrm{kg}$ on day +3 and day +4 posttransplant), tacrolimus, and mycophenolate mofetil as per protocol. All patients received antimicrobial prophylaxis including fluconazole ( $200 \mathrm{mg}$ once a day orally), acyclovir ( $400 \mathrm{mg}$ twice a day orally), and co-trimoxazole, and treatment of febrile neutropenia as per hospital policy. Engraftment was defined by absolute neutrophil count more than $500 / \mu \mathrm{L}$ for three consecutive days and platelet counts more than $20,000 / \mu \mathrm{L}$ for 7 days after last platelet transfusion. GVHD was graded as per Glucksberg criteria and was treated with intravenous methylprednisolone accordingly. After discharge the patients were regularly followed up in outpatient clinics.

\section{Statistical Analysis}

Survival analysis was done using Kaplan-Meier curve analysis using MedCalc version 2.0. Multivariate analysis was performed using Cox proportional regression analysis and log rank test for patients undergoing autologous and allogeneic transplants. Statistical calculation for comparison between matched sibling donor (MSD) and HID HSCT was done using chi-square test or Student's $t$-test as required.

\section{Results}

Out of the 516 patients, who underwent HSCT for hematological malignancies, 348 were males and 168 were females. Median age was 43 years (range: $2-75$ years) ( - Table 1 ). Two hundred fifty-eight (50\%) patients underwent autologous HSCT. Among allogeneic HSCT, 181 were MSD HSCT, 64 were HID HSCT, and 13 were matched unrelated donor (MUD) HSCT. The most common indication for allogeneic HSCT was $\operatorname{AML}(32.4 \%$ ) and the most common indication for autologous HSCT was MM (35.8\%). The most common RIC regimen used was Flu/Mel, and the most common MAC regimen used was $\mathrm{Bu} / \mathrm{Cy}$ ( - Table 1). Grade 1 acute GVHD and grade 2 to 4 acute GVHD developed, respectively, in 4.3 and $26.8 \%$ patients undergoing allogeneic HSCT. All patients with grade 2 to 4 GVHD were treated with intravenous methylprednisolone $1 \mathrm{mg} / \mathrm{kg}$ twice a day as first line treatment. Second line treatment included etanercept $(0.4 \mathrm{mg} / \mathrm{kg}$ twice a week), ruxolitinib (5-10 mg twice a day), or methotrexate. About $11 \%$ patients responded to steroids whereas $36.1 \%$ patient required two or more lines of treatment. Chronic GVHD was seen in $16.3 \%$ patients. Cytomegalovirus (CMV) reactivation was seen in $31.2 \%$ of patients and the patients were treated with intravenous ganciclovir ( $5 \mathrm{mg} / \mathrm{kg}$ twice daily) followed by oral valganciclovir. The 5 -year overall survival (OS) and disease-free survival (DFS) for all HSCTs were 65 and 33\%, respectively. - Table 2 and -Figs. 1 and 2 show the diseasespecific 5-year OS and DFS. Among allogeneic HSCT patients, the 5-year OS was significantly better in the MSD group compared with the HID group (53.6\% vs. $21.7 \%, p<0.001)$, though the 5-year DFS was not significantly different 
64 HSCT for Hematological Malignancies Sharma et al.

Table 1 Characteristics of patients undergoing HSCT for hematological malignancies

\begin{tabular}{|c|c|c|c|}
\hline \multirow{2}{*}{$\begin{array}{l}\text { Total }(n)=516 \\
\text { Males }\end{array}$} & \multirow[b]{2}{*}{348 (67.4\%) } & \multicolumn{2}{|l|}{ Conditioning regimens } \\
\hline & & $\mathrm{Bu}+\mathrm{Cy}$ & 51 \\
\hline Females & $168(32.6 \%)$ & $\mathrm{Cy}+\mathrm{TBI}$ & 32 \\
\hline Median age & 43 y (range: $2-75$ y) & Flu+Mel & 87 \\
\hline \multicolumn{2}{|l|}{ Disease type } & Flu+Cy+TBI (Haplo) & 43 \\
\hline Plasma cell dyscrasia (PCD) & $185(35.8 \%)$ & $\begin{array}{l}\text { Flu+Ara C+ Ida }+ \text { Mel } \\
\text { (sequential) }\end{array}$ & 8 \\
\hline Lymphoproliferative disorder (LPD) & $95(18.4 \%)$ & Flu+Ida + Mel & 13 \\
\hline Acute myeloid leukemia (AML) & $167(32.4 \%)$ & $\mathrm{Flu}+\mathrm{Bu}+\mathrm{Cy}$ & 20 \\
\hline Acute myeloid leukemia (AML) & $69(13.4 \%)$ & Flu+Bu+Thymo & 8 \\
\hline \multicolumn{2}{|l|}{ Transplantation } & Mel & 183 (Mel 200-160/Mel 140 -11) \\
\hline Autologous & 258 & BEAM & 69 \\
\hline MSD allogeneic & 181 & Thio-Treo-Flu & 1 \\
\hline HID allogeneic & 64 & Tubingen & 1 \\
\hline MUD allogeneic & 13 & & \\
\hline \multicolumn{2}{|l|}{ ECOG performance status } & \multicolumn{2}{|l|}{ Viral status } \\
\hline 0 & 23 & HBsAg reactive & 13 \\
\hline 1 & 467 & $\mathrm{HCV}$ reactive & 8 \\
\hline 2 & 22 & HIV positive & 1 \\
\hline 3 & 4 & & \\
\hline
\end{tabular}

Abbreviations: Ara-C, cytarabine; BEAM, BCNU/etoposide/cytarabine/melphalan; Bu, busulfan; Cy, cyclophosphamide; ECOG, Eastern Cooperative Oncology Group; Flu, fludarabine; HCV, hepatitis C virus; HID, haploidentical donor; HIV, human immunodeficiency virus; HSCT, hematopoietic stem cell transplantation; Ida, idarubicin; MSD, matched sibling donor; MUD, matched unrelated donor; TBI, total body irradiation; Thio, thiotepa; Thymo, thymoglobulin; Treo, treosulfan.

Note: LPD includes Hodgkin and non-Hodgkin lymphoma.

Table 2 The OS and DFS for all HSCT patients with hematological malignancies

\begin{tabular}{|l|l|l|l|l|}
\hline Diseases & Mean OS (mo) & 5-year OS & Mean DFS (mo) & $\begin{array}{l}\text { 5-year } \\
\text { DFS }\end{array}$ \\
\hline ALL & 44.49 (SE 4.69), 95\% Cl 35.28-53.68 & $48.7 \%$ & 41.91 (SE 3.85), 95\% Cl 39.36-54.47 & $33.2 \%$ \\
\hline AML & 67.48 (SE 5.95), 95\% Cl 55.80-79.15 & $47.0 \%$ & 52.76 (SE 3.73), 95\% Cl 45.43-60.09 & $41.8 \%$ \\
\hline Hodgkin lymphoma & 76.42 (SE 5.01), 95\% Cl 66.59-86.25 & $83.0 \%$ & 44.36 (SE 4.39), 95\% Cl 35.75-52.97 & $29.5 \%$ \\
\hline Non-Hodgkin lymphoma & 59.90 (SE 5.86), 95\% Cl 48.41-71.39 & $65.0 \%$ & 49.32 (SE 4.31), 95\% Cl 40.88-57.75 & $38.0 \%$ \\
\hline Multiple myeloma & 88.94 (SE 3.70), 95\% Cl 81.67-96.21 & $82.3 \%$ & $44.14(\mathrm{SE} 2.21), 95 \% \mathrm{Cl} 39.81-48.48$ & $29.3 \%$ \\
\hline Overall & $\begin{array}{l}81.74(\mathrm{SE} \mathrm{3.60)} \\
95 \% \text { Cl 84.673-98.820 }\end{array}$ & $65.0 \%$ & $47.19(\mathrm{SE} 1.58)$ ), 95\% Cl 44.094-50.296 & $33.0 \%$ \\
\hline
\end{tabular}

Abbreviations: ALL, acute lymphoblastic leukemia; AML, acute myeloid leukemia; Cl, confidence interval; DFS, disease-free survival; HID, haploidentical donor; HSCT, hematopoietic stem cell transplantation; MSD, matched sibling donor; MUD, matched unrelated donor; OS, overall survival; SE, standard error.

Note: ALL and AML include combined OS and DFS of MSD, HID, and MUD HSCT.

between the two groups ( $42 \%$ vs. $35.7 \%, p=0.247$ ). The overall mortality was $30.8 \%$. The most common cause of death was infection followed by relapse of the disease. Seven patients developed proven or probable fungal pneumonia based on bronchoalveolar lavage or chest computed tomography scan findings. Five patients developed posterior reversible encephalopathy syndrome and there was no death due to bleeding. Gram-negative bacterial infection was seen in $18.4 \%$ of patients and the most common bacteria grown were Escherichia coli, Pseudomonas aeruginosa, Klebsiella, and Enterococcus. Day +100 transplant-related mortality (TRM) of the total cohort was $16.6 \%$.

In multivariate analysis, for allogeneic HSCT, factors impacting OS were chronic GVHD ( $p=0.0272)$, engraftment $(p<0.0001)$, and Eastern Cooperative Oncology Group (ECOG) status $(p=0.0302)$, while diagnosis, acute GVHD, donor source, graft source, mucositis, veno-occlusive disease, and CMV reactivation were not significant. For DFS, significant factors were chronic GVHD $(p=0.0064)$ and engraftment $(p<0.0001)$, while acute GVHD, ECOG status, 


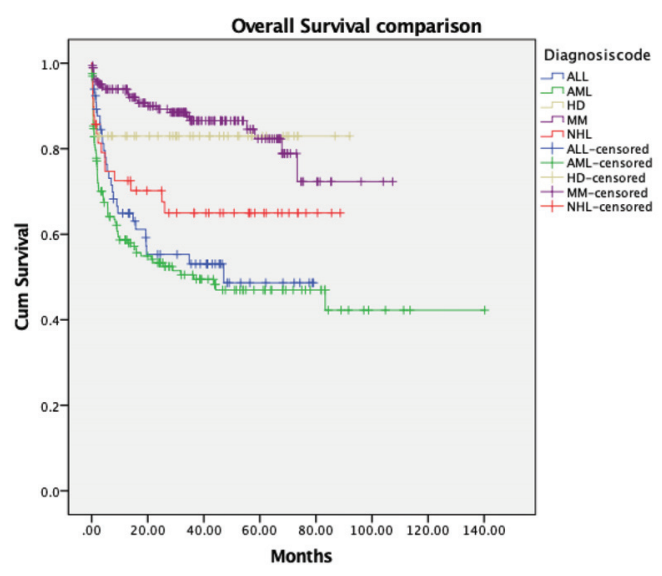

(ALL-Acute lymphoblastic leukemia, AML-Acute myeloid leukemia, HD-Hodgkin lymphoma, NHL-Non Hodgkin lymphoma, MM-multiple myeloma)

Fig. 1 The overall survival of all hematological malignancies.

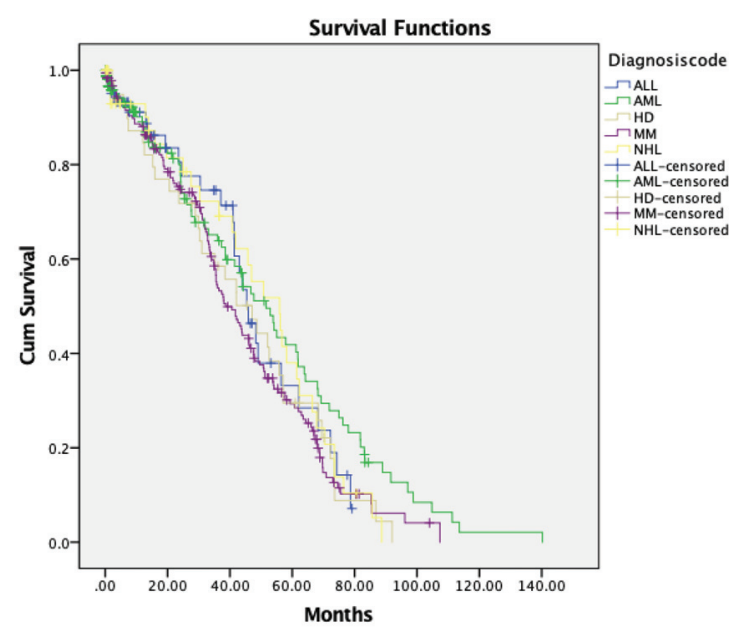

(ALL-Acute lymphoblastic leukemia, AML-Acute myeloid leukemia, HD-Hodgkin lymphoma, NHL-Non Hodgkin lymphoma, MM-Multiple myeloma)

Fig. 2 The disease-free survival of hematological malignancies.

graft source, mucositis, veno-occlusive disease, and CMV reactivation were not significant. Primary graft rejection was seen in three patients that underwent HID, two with AML and one with acute lymphoblastic leukemia (ALL).

\section{Discussion}

India has a large population of 1.39 billion as per estimates in 2021, with increasing proportion of patients being diagnosed with hematological malignancies, requiring HSCT. In India, approximately 19,421 HSCT have been done till 2019 according to the Indian Society for Blood and Marrow Transplantation Registry (ISBMTR-2020). In 2019 alone 2,932 HSCT were performed in India and about one-third of those who underwent allogeneic HSCT were HID HSCT. With the increasing acceptance and availability of better supportive care, increasing number of patients are undergoing HSCT in developing countries, with improved outcomes and lesser cost of transplant. ${ }^{2}$ In our cohort of patients, MM was the most common indication for autologous HSCT followed by Hodgkin lymphoma (HL), whereas AML was the most common indication for allogeneic HSCT followed by ALL. There is scarcity of multicenter data from India, with only few single-center studies available ( - Table 3 ).

\section{Multiple Myeloma}

MM is still the most common indication for autologous HSCT worldwide and in India. Various studies have been reported from the Indian subcontinent. Malhotra et al have reported the median OS of $76.7 \%$ and progression-free survival (PFS) of $55.8 \%$ at 6.5 years. ${ }^{3}$ Kumar et al have reported an estimated OS at 10 and 15 years of 40.4 and $17.7 \%$, respectively, and day +100 TRM of 5.2\%. ${ }^{4}$ Kulkarni et al have reported 5-year OS and PFS of 61.6 and $37.2 \%$, respectively, and TRM of $2.86 \%{ }^{5}$ In our cohort of myeloma patients, the 5-year OS and DFS were 82.3 and 29.3\%, respectively, with mean DFS of approximately 44 months.

\section{Lymphoma}

The age-adjusted incidence rates for non-Hodgkin lympho$\mathrm{ma}(\mathrm{NHL})$ in men and women in India have been reported at 2.9/100,000 and 1.5/100,000, respectively. ${ }^{6}$ Approximately 50 to $60 \%$ of patients with diffuse large B cell lymphoma (DLBCL) achieve and maintain complete remission after firstline therapy, whereas 30 to $40 \%$ relapse and $10 \%$ have refractory disease. ${ }^{7}$ High-dose therapy followed by autologous stem cell transplant (HDT-ASCT) is the mainstay of therapy for RR-DLBCL The landmark PARMA trial has established HDT-ASCT as the standard of care for RR-DLBCL. ${ }^{8}$ In a study from India, in patients with B cell NHL treated with chemotherapy ( $\mathrm{CHOP} \pm \mathrm{R})$, 4-year OS and event-free survival (EFS) were 64.7 and $54 \%$, respectively. ${ }^{9} \mathrm{RR}-\mathrm{NHL}$ remains the major cause of morbidity and mortality. ${ }^{10}$ In a study by Kumar et al, in a similar cohort of patients treated with autologous HSCT, estimated 5-year OS and EFS for patients with RR-HL and NHL were 54.34 and 34.3\%, respectively, and TRM was $7 \% .{ }^{11}$ In our study, the 5-year OS and DFS for RR-HL were 83 and $29.5 \%$ and for RR-NHL were 65 and $38 \%$, respectively, and are comparable to that reported in literature. $^{12,13}$

\section{Acute Myeloid Leukemia}

Allogeneic HSCT is the preferred treatment for intermediateand high-risk AML and for RR-AML. In a study by Ganapule et al, which included 254 consecutive patients who underwent allogeneic-HSCT for AML, the 5-year OS and EFS were 40.1 and $38.7 \%$, respectively. ${ }^{14}$ In the studies comparing RIC versus MAC from the Indian subcontinent, Ganapule et al has reported better OS and EFS with RIC regimen compared with MAC but this was not found in a study by Sharma et al, from similar cohort of patients. ${ }^{14,15}$ Among children (age $\leq 18$ years) with AML who underwent allogeneic HSCT, Arora et al have reported 5-year OS and EFS of 36.3 and 33.3\%, respectively. ${ }^{16}$

In allogeneic HSCTs, matched donor HSCTs are still preferred over HID-HSCTs; however, advances in graft techniques and pharmacological prophylaxis of GVHD have reduced the risks of graft failure and GVHD after HID-HSCT and have made haploidentical stem cell source a viable 
Table 3 Studies of autologous and allogeneic HSCTs reported from India

\begin{tabular}{|c|c|c|c|c|}
\hline Disease & $\begin{array}{l}\text { Number of } \\
\text { patients }\end{array}$ & $\begin{array}{l}\text { Median } \\
\text { age }(y)\end{array}$ & Survival results & Study \\
\hline \multirow[t]{9}{*}{ Multiple myeloma } & 94 & 53 & 6.5-years OS $76.7 \%$ and PFS $55.8 \%$ & Malhotra et $\mathrm{al}^{3}$ \\
\hline & 349 & 52 & $\begin{array}{l}\text { Estimated OS } 40.4 \% \text { at } 10 \text { years and } 17.7 \% \text { at } 15 \\
\text { years }\end{array}$ & Kumar et al ${ }^{4}$ \\
\hline & 245 & 51 & 5 -year OS $61.6 \%$ and PFS $37.2 \%$ & Kulkarni et al ${ }^{5}$ \\
\hline & 85 & 58 & 3-year OS $91 \%$ and PFS 58\% & Gokarn et $\mathrm{al}^{24}$ \\
\hline & 106 & 52 & 2 -year OS $83.4 \%$ and EFS $66.1 \%$ & Sharma et $\mathrm{al}^{25}$ \\
\hline & 141 & 55 & 5 -year OS $72 \%$ and PFS 36\% & Aggarwal et al ${ }^{26}$ \\
\hline & 50 & 56 & 1.4-year OS 86\% & Naithani et a ${ }^{27}$ \\
\hline & 172 & 52 & 5-year OS $72 \%$ and EFS 49\% & Yanamandra and Malhotra ${ }^{28}$ \\
\hline & 66 & 57 & Estimated 5-year OS $82.6 \%$ and EFS $19.1 \%$ & Kumar et al $\left.\right|^{29}$ \\
\hline \multirow[t]{3}{*}{ Lymphoma } & 44 & 35 & 5-year OS 54.34\% and EFS 34.3\% & Kumar et al ${ }^{11}$ \\
\hline & 38 & 28 & 3 -year OS $70.8 \%$ and DFS 66.6\% & Raut et $\mathrm{al}^{30}$ \\
\hline & 23 & - & 39 months OS $65.7 \%$ & Shah et $\mathrm{al}^{31}$ \\
\hline \multirow[t]{6}{*}{ Acute leukemia } & 254 & 34 & $\begin{array}{l}5 \text {-year OS and EFS for RIC and MAC } 67.2 \% \text { versus } \\
38.1 \% \text { and } 63.8 \% \text { versus } 32.3 \% \text {, respectively }\end{array}$ & Ganapule et al ${ }^{14}$ \\
\hline & 126 & 37.5 & $\begin{array}{l}\text { 3-year OS and RFS in RIC } 58.5 \% \text { and } 53.2 \% \text {, } \\
\text { respectively, and 3-year OS and RFS in MAC 59.4\% } \\
\text { and } 53.1 \% \text {, respectively }\end{array}$ & Sharma et al ${ }^{15}$ \\
\hline & 122 & 29 & OS $62 \%$ in MSD and $50 \%$ in HID & Nataraj et $\mathrm{al}^{20}$ \\
\hline & 82 & - & 54-month OS 40\% & Khattry et al ${ }^{32}$ \\
\hline & 46 & 10.7 & $\begin{array}{l}\text { 5-year OS 36.3\% and EFS 33.3\% in pediatric MSD } \\
\text { SCT }\end{array}$ & Arora et al ${ }^{16}$ \\
\hline & 20 & 12 & 2-year OS $64.3 \%$ in pediatric HID SCT & Jaiswal et $\mathrm{al}^{21}$ \\
\hline
\end{tabular}

Abbreviations: EFS, event-free survival; HID, haploidentical donor; HSCT, hematopoietic stem cell transplantation; MAC, myeloablative conditioning; MSD, matched sibling donor; OS, overall survival; PFS, progression-free survival; RFS, relapse-free survival; RIC, reduced intensity conditioning; SCT, stem cell transplant.

alternative for patients lacking an human leukocyte antigenmatched donor. ${ }^{17}$ There are no published randomized comparisons of HID HSCT versus MSD HSCT. Wang et al have compared the outcomes of HID and MSD HSCT groups, the 3year OS rates were 79 and $82 \%(p=0.36)$, and DFS rates were 74 and $78 \%(p=0.34)$, respectively, and the cumulative incidences of relapse were 15 and $15 \%(p=0.98)$, and the nonrelapse mortality rates were 13 and $8 \%(p=0.13)$, respectively. ${ }^{18}$ In a large retrospective study by Ringdén et al, there was no statistically significant difference in probability of relapse between the MSD group when compared with the HID HSCT group but the leukemia-free survival was superior in the MSD group. ${ }^{19}$ Nataraj et al studied MSD and HID HSCT in 122 patients, and there were 38\% deaths in MSD and 50\% deaths in HID HSCT $(p=0.245) .{ }^{20}$ A study by Jaiswal et al on HID in pediatric acute leukemia have reported 2-year OS of $64.3 \% .{ }^{21}$ In our study, the outcome of HID HSCT was inferior compared with MSD HSCT. The OS in the MSD group was significantly lower in HID compared with MSD (21.7\% vs. $52.6 \%, p<0.001)$. This difference was attributed probably to increased risk of infections in the HID transplant. Sepsis was the cause of death in $22 \%$ of MSD compared with $37.5 \%$ of HID HSCT.
Though this real-world data shows variable results of HID compared with MSD transplant, HID HSCT is still a viable treatment option for high-risk patients who either lack an MSD or for those whom a MUD cannot be found or mobilized timely. ${ }^{22}$ Better understanding of the role of T cells, ${ }^{23} \mathrm{~B}$ cells, and antigen presenting cells in the pathophysiology of rejection, and acute and chronic GVHD, has improved the management of transplant-related complications.

\section{Conclusion}

Autologous and allogeneic HSCTs are the curative treatment options for many high-risk and RR hematological malignancies. Though outcome of MSD allogeneic transplant is better than HID transplant, patients having only HID can still be considered for allogeneic HSCT for high-risk diseases. Infections and relapse of the disease post-HSCT are still the major obstacles in the successful outcome of HSCT.

\section{Financial Disclosure}

The authors declare that this study received no financial support. 
Ethics Committee Approval

The protocol and informed consent was approved by the Hospital ethical committee. Informed consent was taken from all the patients.

\section{Funding}

None.

\section{Conflict of Interest}

None declared.

\section{Acknowledgments}

We are thankful to Dr. Anubha for compiling the data and Dr. Ravi for statistical analysis.

\section{References}

1 Bacigalupo A, Ballen K, Rizzo D, et al. Defining the intensity of conditioning regimens: working definitions. Biol Blood Marrow Transplant 2009;15(12):1628-1633

2 Sharma SK, Choudhary D, Gupta N, et al. Cost of hematopoietic stem cell transplantation in India. Mediterr J Hematol Infect Dis 2014;6(01):e2014046

3 Malhotra P, Yanamandra U, Khadwal A, et al. Autologous stem cell transplantation for multiple myeloma: single centre experience from North India. Indian J Hematol Blood Transfus 2018;34(02): 261-267

4 Kumar L, Ramavath D, Kataria B, et al. for AIIMS Myeloma Group. High-dose chemotherapy followed by autologous stem cell transplant for multiple myeloma: predictors of long-term outcome. Indian J Med Res 2019;149(06):730-739

5 Kulkarni U, Devasia AJ, Korula A, et al. Clinical outcomes in multiple myeloma post-autologous transplantation-a single centre experience. Indian J Hematol Blood Transfus 2019;35(02): 215-222

6 Nair R, Arora N, Mallath MK. Epidemiology of non-Hodgkin's lymphoma in India. Oncology 2016;91(Suppl 1):18-25

7 Perry AR, Goldstone AH. High-dose therapy for diffuse large-cell lymphoma in first remission. Ann Oncol 1998;9(Suppl 1):S9-S14

8 Philip T, Guglielmi C, Hagenbeek A, et al. Autologous bone marrow transplantation as compared with salvage chemotherapy in relapses of chemotherapy-sensitive non-Hodgkin's lymphoma. N Engl J Med 1995;333(23):1540-1545

9 Prakash G, Sharma A, Raina V, Kumar L, Sharma MC, Mohanti BK. B cell non-Hodgkin's lymphoma: experience from a tertiary care cancer center. Ann Hematol 2012;91(10):1603-1611

10 Gisselbrecht C, Van Den Neste E. How I manage patients with relapsed/refractory diffuse large B cell lymphoma. $\mathrm{Br} J$ Haematol 2018;182(05):633-643

11 Kumar L, Ganessan P, Ghosh I, Panda D, Gogia A, Mandhania S. Autologous blood stem cell transplantation for Hodgkin and nonHodgkin lymphoma: complications and outcome. Natl Med J India 2010;23(06):330-335

12 Chen Y-B, Lane AA, Logan B, et al. Impact of conditioning regimen on outcomes for patients with lymphoma undergoing high-dose therapy with autologous hematopoietic cell transplantation. Biol Blood Marrow Transplant 2015;21(06):1046-1053

13 Raut LS, Chakrabarti PP. Management of relapsed-refractory diffuse large B cell lymphoma. South Asian J Cancer 2014;3 (01):66-70

14 Ganapule A, Nemani S, Korula A, et al. Allogeneic stem cell transplant for acute myeloid leukemia: evolution of an effective strategy in India. J Glob Oncol 2017;3(06):773-781
15 Sharma SK, Choudhary D, Doval D, et al. Myeloablative versus reduced intensity conditioning regimens for allogeneic hematopoietic stem cell transplant for acute myeloid leukemia and myelodysplastic syndrome: a retrospective analysis. Indian J Hematol Blood Transfus 2020;•*;.. Doi: 10.1007/s12288-020-01386-6

16 Arora S, Pushpam D, Tiwari A, et al. Allogeneic hematopoietic stem cell transplant in pediatric acute myeloid leukemia: lessons learnt from a tertiary care center in India. Pediatr Transplant 2021;25(03):e13918

17 Kanakry CG, de Lima MJ, Luznik L. Alternative donor allogeneic hematopoietic cell transplantation for acute myeloid leukemia. Semin Hematol 2015;52(03):232-242

18 Wang Y, Liu Q-F, Xu L-P, et al. Haploidentical vs identical-sibling transplant for AML in remission: a multicenter, prospective study. Blood 2015;125(25):3956-3962

19 Ringdén O, Labopin M, Ciceri F, et al. Is there a stronger graftversus-leukemia effect using HLA-haploidentical donors compared with HLA-identical siblings? Leukemia 2016;30(02): 447-455

20 Nataraj KS, Prabhu S, Bhat S, et al. Hematopoietic stem cell transplant outcomes in patients with acute myeloid leukemia from a tertiary care center in South India. Biol Blood Marrow Transplant 2020;26(03):S123-S124

21 Jaiswal SR, Chakrabarti A, Chatterjee S, et al. Haploidentical peripheral blood stem cell transplantation with post-transplantation cyclophosphamide in children with advanced acute leukemia with fludarabine-, busulfan-, and melphalan-based conditioning. Biol Blood Marrow Transplant 2016;22(03): 499-504

22 Fabricius WA, Ramanathan M. Review on haploidentical hematopoietic cell transplantation in patients with hematologic malignancies. Adv Hematol 2016;2016:5726132

23 Sharma SK. What a clinical hematologist should know about $\mathrm{T}$ cells? Int Blood Res Rev 2020:20-32

24 Gokarn A, Bonda A, Mathew L, et al. High dose chemotherapy with autologous stem cell transplantation for multiple myeloma: outcomes at Tata Memorial Centre. Clin Lymphoma Myeloma Leuk 2017;17(01):e126

25 Sharma SK, Choudhary D, Kumar M, et al. Stem cell transplant for multiple myeloma: a single center experience from Northern India. J Hematol Oncol 2018;31:1010

26 Aggarwal M, Agrawal N, Yadav N, et al. Autologous stem cell transplantation in first remission is associated with better progression-free survival in multiple myeloma. Ann Hematol 2018; 97(10):1869-1877

27 Naithani R, Dayal N, Rai R, Pathak S, Singh M. Autologous hematopoietic stem cell transplantation for multiple myeloma in India. Indian J Hematol Blood Transfus 2018;34(03): 564-565

28 Yanamandra U, Malhotra P. Stem cell transplantation in multiple myeloma: very much alive and kicking. Indian J Hematol Blood Transfus 2019;35(02):205-207

29 Kumar J, Nair R, Radhakrishnan V, et al. Autologous Stem cell transplantation in multiple myeloma: experience of a single center from Eastern India. Clin Lymphoma Myeloma Leuk 2019; 19:S326

30 Raut S, Shah S, Shah K, et al. Improving outcome of Hodgkin's disease with autologous hematopoietic stem cell transplantation. Indian J Hematol Blood Transfus 2016;32(02):176-181

31 Shah CA, Karanwal A, Desai M, Pandya M, Shah R, Shah R. Hematopoietic stem-cell transplantation in the developing world: experience from a center in Western India. J Oncol 2015;2015:710543

32 Khattry N, Laskar S, Sengar M, et al. Long term clinical outcomes of adult hematolymphoid malignancies treated at Tata Memorial Hospital: an institutional audit. Indian J Cancer 2018;55(01):9-15 